\title{
Evaporation and Climate
}

\author{
Oleg Khalidullin* \\ Kazakh National University, Kazakhstan \\ *Corresponding author: Oleg Khalidullin, Independent Researcher, Almaty, Republic of Kazakhstan, Kazakhstan. \\ To Cite This Article: Oleg Khalidullin. Evaporation and Climate. Am J Biomed Sci \& Res. 2019 - 2(1). AJBSR.MS.ID.000561. \\ DOI: 10.34297/AJBSR.2019.02.000561
}

Received: March 14, 2019 | Published: March 21, 2019

\section{Opinion}

HG Wells has long described the future of mankind in The Time Machine. It is divided into two parts. All the elite - Eloi, will sing and have fun, enjoying the outdoors, eating exclusively vegetable food and fruit. We believe that these are all descendants of the oligarchs, the bureaucracy and the rest of the non-working population. They do nothing, they sleep in big houses without locks. The second part - merlocks - will live underground, produce clothing and footwear for eloi. The vision of the merlock is adapted to the dark. At night, they enter the houses and select the next suitable adult individuals, drag them to their dungeon and eat them. The climate is preserved because there is no arable land, no reservoirs, no landfills. There are no power plants, factories, roads, cities, cars, asphalt.

Climate depends on fumes. It is believed that the evaporation of the oceans exceeds the evaporation from land because 3 times the area of the oceans exceeds the area of inhabited land. Many do not know that the total area of leaves of plant cover increases the land area and evaporation by 3 times. It follows that, historically, both land and oceans evaporate from the same area. Evaporated before the development of the industry.

Artificial evaporation - the transformation into water vapor, devoid of its main function - the solvent and carrier of microelements in food chains - differ from natural evaporation by quality, volume and speed. Water supplies trace elements to plants and animals dissolved underground and along river beds. Entering the bodies of organisms and the roots of plants with one structure, water is repeatedly transformed into blood, lymph, many other body organs, plant sap, and enters the atmosphere as an exhalation, drying secretions, transpiration in a completely different quality. The sum of all these, purely individual vapors, forms a substance in the atmosphere in the form of clouds, with certain properties, ground for millions of years in each area, which fall on the beaten path with a given frequency of precipitations in the given places of the planet, maintaining different ranges from deserts to tropics. Perhaps, the information component plays some role here. It is known that clusters of molecules carry information about their source - maybe DNA. For example, it is known that the smell is formed by molecules inherent in each individual.
The properties of clouds are their saturation, physical and chemical composition, specific gravity, height above the surface of the planet, volume, time spent in the atmosphere. Together with temperatures, pressures, electrical charges, a sedimentation mechanism is created, which strictly determines where, how much and when it is necessary to deliver moisture to every place on the planet (Figure 1).

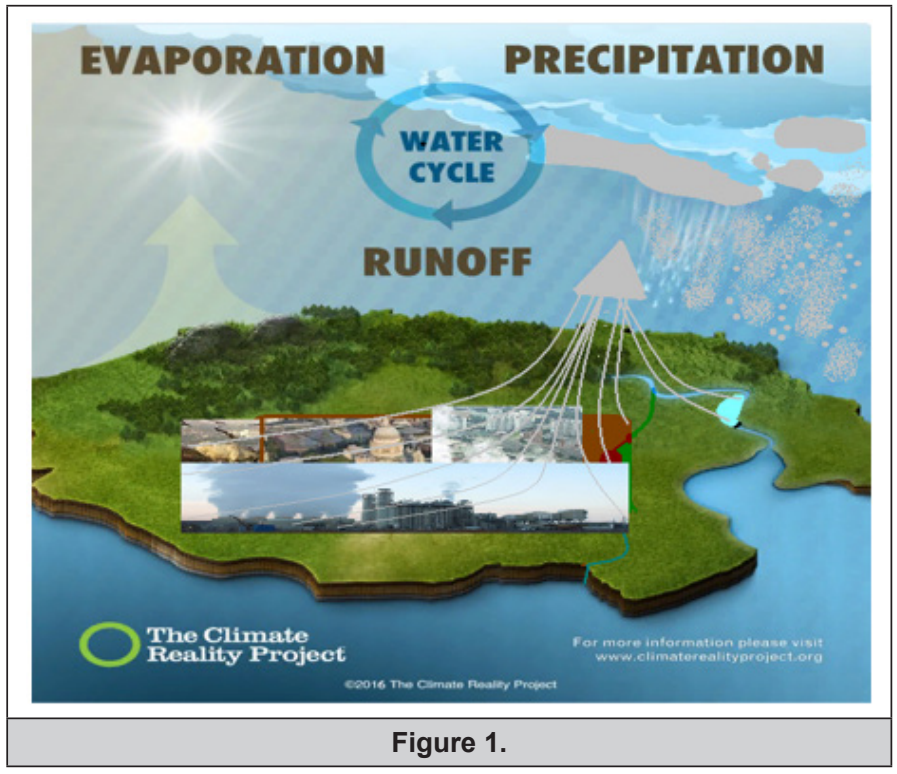

We took away almost all of the land from nature by cutting down forests, plowing the soil, flooding them with water in front of hydroelectric power plants, using unnatural water-turning it into a working reagent. We move it with pumps, we wash everything around us and ourselves with it. We boil, heat, compress, cool, fill the fields, destroy its molecules in the air with engines, furnaces and compressors. Evaporation from all these processes must not have the properties inherent in pairs from living organisms and plants. The physical, chemical, and all other cloud parameters have changed. The mechanism of atmospheric transformations has changed, which produces new clouds in a new way, concentrates and distributes all the moisture in a different way, changes the places of precipitation. 
The volumes of artificial evaporation with the development of industry and human comfort have become comparable, and maybe they have become equal to the volume of organic evaporation. Mankind destroyed the effect of organic vapor on 70 percent of the land. From these places, the waters that did not pass the path indicated by nature began to evaporate - to deliver nutrients to living organisms and plants. In total, we take 22 cubic kilometers of water from open and underground sources. All these waters are devoid of natural functions and evaporate without changing the structure [1].

The new quality of vapor has changed the structure of steam in such a way that it affected its specific weight. The increased weight of gaseous water and its drops changed the location of clouds along the height of the atmosphere. Heavy clouds cannot rise to the height at which the process of sedimentation was built in the preindustrial era. Burdened pairs of artificial vapors cannot rise to a predetermined height. Therefore, the clouds have become slower in terms of speed of movement and increased the concentration in volumes. Changed the time the water in the clouds. All this in the complex changed the places of precipitation, their volumes and schedule. From here, we observe floods in some areas, droughts in others, the extinction of insect species and animals. The decrease in transit over the range and height of the movement of clouds led to a decrease in precipitation on the glaciers of the polar poles and mountain peaks. The precipitations on the way to these places do not accumulate in the glaciers, but replenish the oceans with additional volumes. Therefore, the level of the oceans increases and the ice layer of the glaciers decreases.
Therefore, there are floods, droughts, the level of the oceans rises - heavy clouds do not reach the mountain glaciers and the polar regions. US President D. Trump is right - he has an intuition, but there is no correct explanation for the climate. This hypothesis requires scientific proof or refutation. Its proof should lead to a new strategy, which should be based on stopping deforestation, creating man-made water reservoirs, deep plowing fields, eliminating landfills, reducing the area of buildings and roads and total water savings in all agricultural, municipal, industrial and all other enterprises. human activities. Nature's return to its natural process of circulation. Opportunities are there, if you use the experiences of developed countries. It is known that in the Scandinavian countries there are no landfills, in Israel they grow plant products with minimal water consumption. Famous houses with vertical and roof landscaping. Known inventions that allow to generate electricity without reservoirs. There are ways to save water in planes and trains. Such and other measures of total water saving should be applied in all cities and countries.

Only the return of its nature, millions of years of accumulated technology of the water cycle, can reduce natural disasters and stop climate change. To prove the hypothesis, it is necessary to study its basic elements. For this, a new team of new specialists is needed, which will be able to bring the scientific base and turn the consciousness of the sleeping population in a carbonic intoxication.

\section{References}

1. Oleg Khalidullin (2019) True Reason for Climate Change. Am J Biomed Sci \& Res 1(3): 122-123. 